\title{
Leptin Rapidly Improves Glucose Homeostasis in Obese Mice by Increasing Hypothalamic Insulin Sensitivity
}

\author{
Christiane Koch, ${ }^{1}$ Rachael A. Augustine, ${ }^{2}$ Juliane Steger, ${ }^{1}$ Goutham K. Ganjam, ${ }^{1}$ Jonas Benzler, ${ }^{1}$ Corinna Pracht, ${ }^{1}$ \\ Chrishanthi Lowe, ${ }^{1}$ Michael W. Schwartz, ${ }^{4}$ Peter R. Shepherd, ${ }^{3}$ Greg M. Anderson, ${ }^{2}$ David R. Grattan, ${ }^{2}$ \\ and Alexander Tups ${ }^{1}$ \\ ${ }^{1}$ Department of Animal Physiology, Faculty of Biology, Philipps University Marburg, D-35043 Marburg, Germany, ${ }^{2}$ Centre for Neuroendocrinology and \\ Department of Anatomy and Structural Biology, University of Otago, Dunedin 9054, New Zealand, ${ }^{3}$ Maurice Wilkins Centre for Molecular Biodiscovery \\ and Department of Molecular Medicine and Pathology, University of Auckland, 92019 Auckland, New Zealand, and ${ }^{4}$ Division of Metabolism, Endocrinology \\ and Nutrition, University of Washington, Seattle, Washington 98195
}

Obesity is associated with resistance to the actions of both leptin and insulin via mechanisms that remain incompletely understood. To investigate whether leptin resistance per se contributes to insulin resistance and impaired glucose homeostasis, we investigated the effect of acute leptin administration on glucose homeostasis in normal as well as leptin- or leptin receptor-deficient mice. In hyperglycemic, leptin-deficient Lep ${ }^{\mathrm{ob} / \mathrm{ob}}$ mice, leptin acutely and potently improved glucose metabolism, before any change of body fat mass, via a mechanism involving the $110 \alpha$ and $\beta$ isoforms of phosphatidylinositol-3-kinase (PI3K). Unlike insulin, however, the anti-diabetic effect of leptin occurred independently of phospho-AKT, a major downstream target of PI3K, and instead involved enhanced sensitivity of the hypothalamus to insulin action upstream of PI3K, through modulation of IRS1 (insulin receptor substrate 1) phosphorylation. These data suggest that leptin resistance, as occurs in obesity, reduces the hypothalamic response to insulin and thereby impairs peripheral glucose homeostasis, contributing to the development of type 2 diabetes.

\section{Introduction}

In addition to its essential role in the control of body weight, the adipose tissue-derived hormone, leptin, contributes to the maintenance of glucose homeostasis (Pelleymounter et al., 1995; Muzzin et al., 1996; Schwartz et al., 1996; Farooqi et al., 1999; Yu et al., 2008). In fact, recent data suggest that leptin is more potent at regulating glucose levels in blood than it is at suppressing appetite (Hedbacker et al., 2010). As the effect of leptin on glucose homeostasis is likely to be mediated centrally via activation of specific neuronal subpopulations in the hypothalamus (Kievit et al., 2006; German et al., 2009; Hill et al., 2009; Hedbacker et al., 2010), in the present study, we aimed to investigate the central mechanisms mediating the anti-diabetic properties of leptin. Leptin action on glucose homeostasis is dependent on signal transduction via phosphatidylinositol-3-kinase (PI3K) activity (Mauvais-Jarvis et al., 2002; Niswender et al., 2003; Morton et al., 2005; Hill et al., 2009), a pathway also used by the insulin receptor. We have recently shown that unlike insulin, leptin does not induce phosphorylation of AKT, a key downstream mediator of insulin-stimulated PI3K activity, in the hypothalamus (Tups et al., 2010). Since insulin action in the CNS is also implicated in the

\footnotetext{
Received June 22, 2010; revised Sept. 24, 2010; accepted Sept. 28, 2010.

This study was funded by the German Ministry of Education and Research (Ref. No: 0315087, to A.T.) and the Health Research Council of New Zealand (to G.M.A. and D.R.G.).

Correspondence should be addressed to Dr. Alexander Tups, Department of Animal Physiology, Faculty of Biology, Philipps University Marburg, Karl-von-Frisch Strasse 8, D-35043 Marburg, Germany. E-mail: alexander.tups@ staff.uni-marburg.de.

DOI:10.1523/JNEUROSCI.3202-10.2010

Copyright $\odot 2010$ the authors $\quad 0270-6474 / 10 / 3016180-08 \$ 15.00 / 0$
}

regulation of peripheral glucose homeostasis (Brüning et al., 2000; Okamoto et al., 2004, 2005), we hypothesized that leptin might exert its glucose-lowering effects in part through an interaction with insulin signaling in the hypothalamus. Using a range of leptin- and leptin receptor-deficient mice, we demonstrate here that leptin rapidly and markedly enhances hypothalamic sensitivity to insulin. These data provide new insight into mechanisms underlying impaired glucose homeostasis in obesity.

\section{Materials and Methods}

Animals

In all experiments only male animals were analyzed. Mice were either purchased from Janvier or drawn from the breeding colonies of the University of Marburg (Marburg, Germany) or the University of Otago, (Dunedin, New Zealand). Sprague Dawley rats were purchased from the Animal Facility, University of Otago. Neuronspecific Lepr knock-out mice (Lepr ${ }^{\text {flfl }} \times$ CaMKII $\alpha$-Cre) were generated at the University of Otago as described previously (Quennell et al., 2009). All animals were 8-13 weeks old and housed individually under standard conditions with a light/dark cycle of $12 \mathrm{~h}$. The ambient temperature for mice was $26^{\circ} \mathrm{C}$, for rats $23^{\circ} \mathrm{C}$. Apart from the dark phase before the experiments, all animals had access to standard rodent diet and water ad libitum.

Stereotaxic implantation of intracerebroventricular cannulae Mouse. Under isoflurane anesthesia (CP-Pharma) and carprofen analgesia (5 mg/kg; Rimadyl, Pfizer) a stainless steel guide cannula (internal cannula $2.8 \mathrm{~mm}$ with $1 \mathrm{~mm}$ projection 33 gauge, C315I-5/Spc, Plastics One) was stereotaxically implanted into the lateral cerebral ventricle of 7-week-old Lep ${ }^{\mathrm{ob} / \mathrm{ob}}$ mice (0.9 lateral and 0.1 posterior to bregma, 2.2 ventral to the surface of the skull). The cannula was fixed with dental 
cement on one small steel screw (screw 00-96x1/96). Cannula placement was tested with an angiotensin II (Sigma-Aldrich) injection [5 ng in $2 \mu$ l of artificial CSF (aCSF)] $5 \mathrm{~d}$ after surgery. Mice were observed after injection and were only chosen for the experiment if they drank immediately.

Rat. Under isoflurane anesthesia (CP-Pharma) and carprofen analgesia (5 mg/kg; Rimadyl, Pfizer), a stainless steel guide cannula (internal cannula $4 \mathrm{~mm}$ with $1 \mathrm{~mm}$ projection 28 gauge, C313I/Spc, Plastics One) was stereotaxically implanted into the lateral cerebral ventricle of 7 -week-old male rats ( 1.3 lateral to bregma; 3.0 ventral to the surface of the skull). The cannula was fixed with dental cement on three steel screws (0-80x3/32; Plastics One), which were placed around the cannula. Five days after surgery, correct cannula placement was verified by injecting angiotensin II ( $20 \mathrm{ng}$ in $2 \mu \mathrm{l}$ of aCSF). Rats that drank $<5 \mathrm{ml}$ water in 30 min were excluded from the experimental treatment.

\section{Food restriction experiment}

During the first $8 \mathrm{~d}$ of the experiment a group of Lep ${ }^{\mathrm{ob} / \mathrm{ob}}$ mice was pair-fed to Lep ${ }^{\mathrm{ob} /+}$ mice whereas one group of Lep ${ }^{\mathrm{ob} / \mathrm{ob}}$ mice was fed ad libitum ( $n=10$ animals/group). Despite being pair-fed Lep ${ }^{\mathrm{ob} / \mathrm{ob}}$ mice still had a significantly higher body weight compared with Lep ${ }^{\text {ob/+ }}$ mice after $8 \mathrm{~d}$. The amount of food given to the animals was subsequently reduced to $2-3 \mathrm{~g} / \mathrm{d}$ to match the body weight of $\mathrm{Lep}^{\mathrm{ob} /+}$ mice. When the body weight trajectories of the Lep ${ }^{\mathrm{ob} / \mathrm{ob}}$ and the Lep ${ }^{\mathrm{ob} /+}$ mice were similar (8 weeks of age), the food-restricted group of Lep ${ }^{\text {ob/ob }}$ mice was subdivided into two weight-matched groups ( $n=4-6$ animals/group), one of which received an intraperitoneal vehicle (PBS) injection and one an intraperitoneal leptin injection (1.25 mg/kg in PBS). The intraperitoneal glucose tolerance test (ipGTT) was performed in the morning, whereas on the same day in the afternoon the body composition was analyzed under isoflurane anesthesia (CP-Pharma) via DEXA-scan (Lunar PIXImus Densitometer; GE Medical Systems).

Glucose tolerance tests in leptin-or leptin receptor-deficient mice Three different obese mouse strains (Lepr ${ }^{\mathrm{db} / \mathrm{db}} ;$ Lepr $^{f l f l} \times$ CaMKII $\alpha$-Cre and Lep ${ }^{\mathrm{ob} / \mathrm{ob}}$ ) and their controls (Lepr ${ }^{\mathrm{db} /+}, \operatorname{Lepr}^{\mathrm{f} / \mathrm{fl}}$, and Lep ${ }^{\mathrm{ob} /+}$ ) were subjected to an ipGTT. All animals were 8 weeks old except Lepr fllfl $\times$ CaMKII $\alpha$-Cre and the respective control Lepr ${ }^{\text {fl/fl }}$, which were at 13 weeks of age, and were food deprived for $16 \mathrm{~h}$ before the experiment. The individual strains received an intraperitoneal injection of either vehicle (PBS) or leptin (1.25 mg/kg, i.p., in PBS) $15 \mathrm{~min}$ before glucose application ( 1 g glucose $/ \mathrm{kg}$, i.p.; $n=4-6$ animals/group). To determine the blood glucose the vena facialis was punctuated and the glucose concentration was detected by using a commercially available glucometer (Roche; Accu-Check Performa). Lep ${ }^{\text {ob/ob }}$ mice were divided into three groups, the first one received the leptin injection as stated above $15 \mathrm{~min}$ before the glucose tolerance test (GTT), the second was injected $90 \mathrm{~min}$ before the GTT and the third group received two injections 540 and 60 min before the GTT.

\section{Glucose tolerance test after intracerebroventricular injection of} leptin and isoform-specific PI3K inhibitors

Lep ${ }^{\text {ob/ob }}$ mice ( 8 weeks of age) that were deprived for $16 \mathrm{~h}$ food before the experiment, received an intracerebroventricular injection of isoformspecific PI3K inhibitors (PIK-75/TGX-221 $0.1 \mathrm{~nm}$ in 5\% DMSO/aCSF) or $5 \% \mathrm{DMSO} / \mathrm{aCSF}$ followed by an intracerebroventricular injection of leptin ( $4 \mu \mathrm{g}$ in aCSF) or aCSF $45 \mathrm{~min}$ later ( $n=5-6$ animals/group). One hour after leptin application, an intraperitoneal GTT (1 g glucose $/ \mathrm{kg}$ ) was performed. Blood was collected from the vena facialis and analyzed as described above.

\section{Insulin-induced phosphorylation of AKT (Ser473)}

Three different mouse strains (Lepr ${ }^{\mathrm{db} / \mathrm{db}} ;$ Lepr $^{f l f l} \times$ CaMKII $\alpha-C r e$; $\mathrm{Lep}^{\mathrm{ob} / \mathrm{ob}}$ ) and their respective controls $\left(\operatorname{Lepr}^{\mathrm{db} /+}\right.$, Lepr $^{\text {fl/fl }}$, Lep $^{\mathrm{ob} / \mathrm{ob}}$, $\mathrm{Lep}^{\mathrm{ob} /+}$ ) were fasted for $24 \mathrm{~h}$ and perfused in the middle of the light phase. Mice lacking forebrain or global leptin receptor and their appropriate controls were divided into two groups. Accordingly one of the two groups received an injection of insulin ( $1 \mathrm{mg} / \mathrm{kg}$, i.p.; $n=3-6$ animals/ group), the other one vehicle (PBS; $n=3-4) 15$ min before transcardial perfusion with $4 \%$ paraformaldehyde/phosphate buffer under pentobar- bital anesthesia (Narcoren; Merial GmbH). In a different experiment, $\mathrm{Lep}^{\mathrm{ob} / \mathrm{ob}}$ mice and heterozygous controls $\left(\mathrm{Lep}^{\mathrm{ob} /+}\right.$ ) were each divided into four groups that received two injections $15 \mathrm{~min}$ apart. The first group received two vehicle injections, the second vehicle followed by insulin, the third leptin followed by vehicle and the fourth leptin followed by insulin. The animals were transcardially perfused 15 min after the second injection (vehicle/vehicle $n=2$ animals/group; all other groups $n=4$ animals/group).

\section{Effect of leptin on phosphorylation of phospho-IRS(Ser307} and Ser612)

Nine-week-old male Lep ${ }^{\text {ob/ob }}$ mice were fasted for $16 \mathrm{~h}$ and divided into two groups ( $n=5-6$ animals/group). The first group received an intracerebroventricular leptin injection ( $4 \mu \mathrm{g}$ in aCSF) and the other $5 \%$ $\mathrm{DMSO} / \mathrm{aCSF}$. Fifteen minutes later mice were perfused with $4 \%$ paraformaldehyde/phosphate buffer under pentobarbital anesthesia (Narcoren; Merial $\mathrm{GmbH}$ ) and brains were analyzed by immunohistochemistry.

\section{Characterization of hypothalamic insulin signaling after} antagonism of leptin signaling

After $24 \mathrm{~h}$ food restriction, 8-week-old Sprague Dawley rats $(n=3-4$ animals/group) received an intracerebroventricular injection of aCSF or a competitive rat leptin antagonist (200 $\mu \mathrm{g}$ in aCSF; L39A/D40A/F41A Protein Laboratories Rehovot) (Solomon et al., 2006) directly followed by an intracerebroventricular injection of insulin (10 mU) or leptin $(4 \mu \mathrm{g}$ in aCSF; R\&D Systems). Fifteen minutes later rats were transcardially perfused with $4 \%$ paraformaldehyde/phosphate buffer under pentobarbital anesthesia (Narcoren; Merial GmbH).

\section{Immunohistochemistry}

For immunohistochemistry, animals were anesthetized with pentobarbital (Narcoren; Merial GmbH) and perfused with $0.9 \%$ saline containing heparin followed by $4 \%$ paraformaldehyde in $0.1 \mathrm{~m}$ phosphate buffer, $\mathrm{pH}$ 7.4. Brains were removed and stored in the same solution for $1 \mathrm{~d}$ followed by dehydration in $30 \%$ sucrose $/ 0.1 \mathrm{~m}$ phosphate buffer. When brains had sunk, they were frozen in isopentane, cooled on dry ice for $1 \mathrm{~min}$, and sectioned coronally at $35 \mu \mathrm{m}$ throughout the hypothalamus on a freezing microtome. Brain slides were collected in four series and stored in cryoprotectant at $4^{\circ} \mathrm{C}$. Free-floating sections were incubated in $0.3 \% \mathrm{H}_{2} \mathrm{O}_{2}$ diluted in $\mathrm{PB}$ for 15 min to quench endogenous peroxide followed by incubation in blocking solution ( $1 \%$ normal goat serum, 5\% BSA, $0.5 \%$ Triton X-100 in phosphate buffer) for $60 \mathrm{~min}$. Sections were incubated with the primary antibody overnight at $4^{\circ} \mathrm{C}$ (anti-phospho-AKT Ser473, IHC-specific; catalog \#9277, or anti-phospho-IRS1 Ser612; cat. no 3203, or anti-phospho-IRS1 Ser 307 catalog \#2381; Cell Signaling Technology) diluted in blocking-solution (both 1:500). On the day after, sections were incubated with a biotinylated secondary goat anti-rabbit antibody for $1 \mathrm{~h}$ (1:1000, in blocking solution containing $1 \%$ normal goat serum, $3 \%$ BSA, $0.5 \%$ Triton X-100), and then treated with ABC (Vector Laboratories) solution for $1 \mathrm{~h}$. Between the steps, all sections were washed in phosphate buffer (containing $0.5 \%$ Triton X-100 before secondary antibody). Finally, the signal was developed by nickel-diaminobenzidine solution (Vector Laboratories), giving a gray/black precipitate. Section images were captured by using a digital camera mounted on a microscope.

\section{Statistics}

Data were analyzed by one- or two-way ANOVA followed by a HolmSidak comparison test, as appropriate, using SigmaStat statistical software (Jandel). Where data failed equal variance or normality tests they were analyzed by one-way ANOVA on ranks followed by Dunn's multiple-comparison test. Results are presented as means \pm SEM, and differences were considered significant if $p<0.05$.

\section{Results}

To separate the role of hypothalamic leptin action on glycemia from its effects on body fat mass, we food-restricted obese (and diabetic) leptin-deficient Lep ${ }^{\text {ob/ob }}$ mice such that their body weight trajectory matched that of lean Lep ${ }^{\text {ob/+ }}$ controls (Fig. 1a). 
a

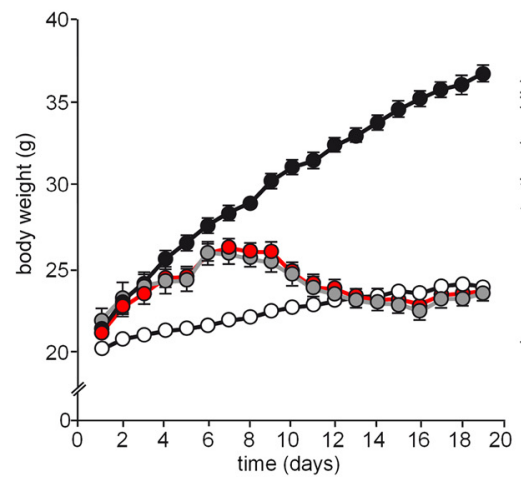

b

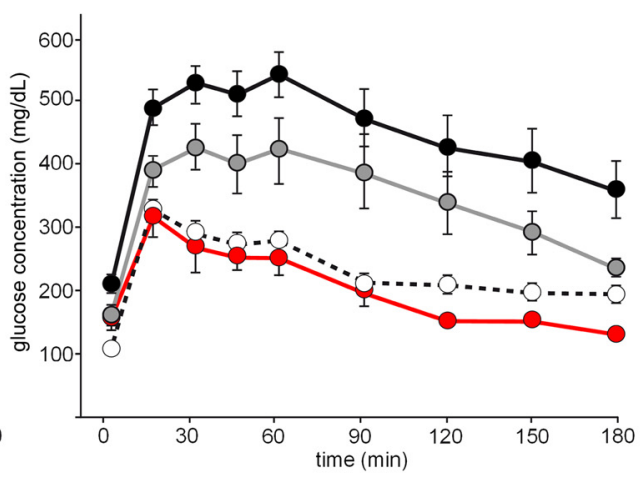

C

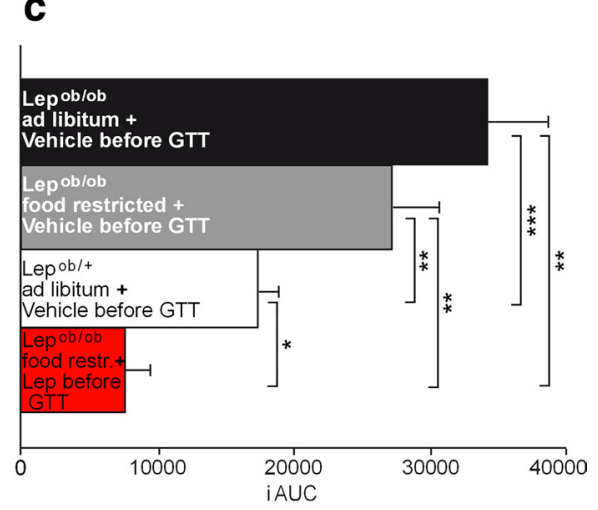

d

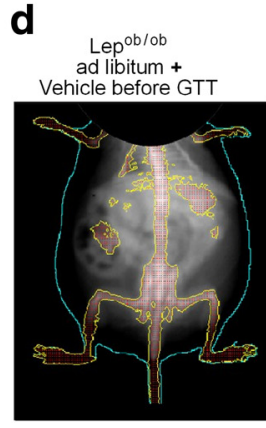

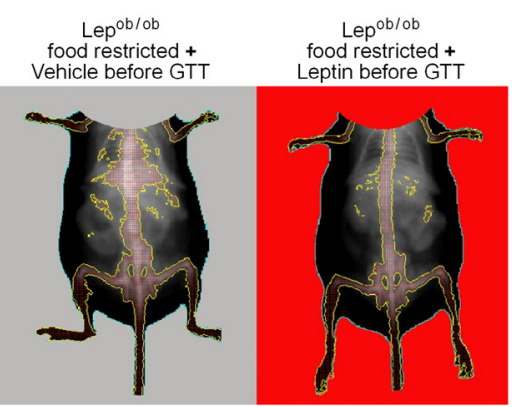

Lep ${ }^{\mathrm{ob} /+}$ Vehicle before GTT

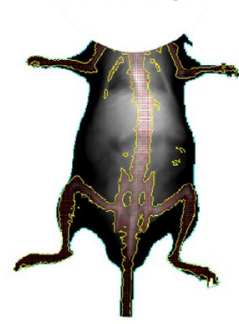

e

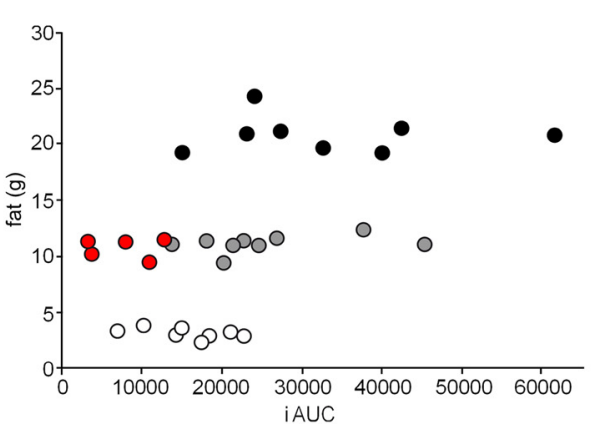

Figure 1. Body weight, glucose concentration, and associated AUC and body composition of Lep ${ }^{\mathrm{ob} / \mathrm{ob}}$ mice after food restriction. $\boldsymbol{a}$, Body weight trajectory of Lep ${ }^{\text {ob/ob }}$ mice (black; $n=10$ ) and control Lep ${ }^{\mathrm{ob} /+}$ mice (white; $n=10$ ). Two subgroups of Lep ${ }^{\mathrm{ob} / \mathrm{ob}}$ mice (red and gray; $n=4-6$ animals/group) were pair-fed during the first $8 \mathrm{~d}$ of the experiment followed by a further reduction of available food to 2-3 g/d to match the body weight of the controls. Data show means \pm SEM. $\boldsymbol{b}, \boldsymbol{c}$, ipGTT (b) and integrated AUC (c) of food-restricted Lep ${ }^{\text {ob/ob }}$ mice pretreated with PBS or leptin $(1.25 \mathrm{mg} / \mathrm{kg}) 15 \mathrm{~min}$ before glucose application $(1 \mathrm{~g} / \mathrm{kg})$. White, Ad libitum-fed vehicle (PBS)-treated Lep ${ }^{\text {ob/+ }}$ mice; red, food-restricted leptin-treated Lep ${ }^{\text {ob/ob }}$ mice; gray, food-restricted vehicle (PBS)-treated Lep ${ }^{\text {ob/ob }}$ mice; black, ad libitum-fed vehicle (PBS)-treated Lep ${ }^{\text {ob/ob }}$ mice. Data show means \pm SEM. ${ }^{*} p<0.05,{ }^{* *} p<0.01,{ }^{* * *} p<0.001$. d, Representative DEXA-Scan images of one animal in each treatment group. The image was taken immediately after the ipGTT was performed. e, Correlation of AUC and body fat mass of ad libitum-fed Lep ob/+ mice, ad libitum-fed Lep ${ }^{\mathrm{ob} / \mathrm{ob}}$ mice, and slim pair-fed/food-restricted Lep ${ }^{\mathrm{ob} / \mathrm{ob}}$ mice, which received a vehicle or leptin injection. Note the lack of correlation between fat content in GTT AUC in individual treatment groups.

Despite the fact that food-restricted Lep ${ }^{\text {ob/ob }}$ mice had the same body weight and fasting glucose levels as their heterozygous littermates (Fig. 1a), they remained glucose intolerant as determined by an intraperitoneal GTT after $20 \mathrm{~d}$ of food restriction $(p=0.007$; Fig. $1 b, c)$ and exhibited $11 \%$ reduced bone mineral density $\left(0.041 \mathrm{~g} / \mathrm{cm}^{3}\right)$ compared with their heterozygous littermates $\left(0.046 \mathrm{~g} / \mathrm{cm}^{3} ; p<0.001\right)$. It is important to acknowledge that food-restricted Lep ${ }^{\text {ob/ob }}$ mice continued to have a higher fat content, as measured by dual energy x-ray absortiometry (DEXA; $p<0.001$; Fig. 1d). Within these groups, however, there was no correlation between body fat and glucose homeostasis as measured by the GTT (Fig. 1e). While food restriction did not effectively improve glucose metabolism, plasma glucose levels were completely normalized in these mice following intraperitoneal injection of leptin $(p<0.018$ compared with food restricted controls; Fig. 1b,c).

Having established that leptin administration improves glucose tolerance in food-restricted Lep ${ }^{\text {ob/ob }}$ mice, we next investigated whether this beneficial effect is intact in Lep ${ }^{\text {ob/ob }}$ mice allowed to feed ad libitum. As expected, vehicle-treated Lep ${ }^{\text {ob/ob }}$ mice exhibited severe hyperglycemia and impaired glucose tolerance compared with Lep ${ }^{\text {ob/+ }}$ mice (Fig. $\left.2 a, b\right)(p<0.05)$. As was observed in food-restricted animals, intraperitoneal leptin administration normalized glucose tolerance in Lep ${ }^{\mathrm{ob} / \mathrm{ob}}$ mice $(p=$ 0.016 vs heterozygous controls; Fig. $2 a$ ). This effect was maximal when leptin was acutely administered as little as $15 \mathrm{~min}$ before the glucose challenge, and was not further enhanced by extending leptin pretreatment for up to $9 \mathrm{~h}$ before the GTT (data not shown). Since the response to leptin did not vary between time points, a leptin injection $60 \mathrm{~min}$ before GTT was chosen for subsequent experiments to minimize stress due to injection handling. By comparison, in euglycemic, nondiabetic heterozygous control animals, exogenous leptin had no effect on glucose tolerance (Fig. 2b).

To determine whether the effects of intraperitoneal leptin on glucose homeostasis were mediated centrally or peripherally, we investigated whether leptin receptor deletion specifically in forebrain neurons [Lepr ${ }^{f l / f l} \times$ CaMKII $\alpha$-Cre (Quennell et al., 2009)] disrupted leptin's glucose-lowering effect. As seen in Lep ${ }^{\text {ob/ob }}$ mice glucose tolerance was markedly impaired in these animals compared with controls lacking Cre-recombinase (Fig. $2 c)$ ( $p=$ $0.0134)$. The degree of impaired glucose tolerance in these animals was very similar to that seen in Lepr ${ }^{\mathrm{db} / \mathrm{db}}$ mice, which lack a functional leptin receptor in the whole body. Unlike the effect seen in Lep ${ }^{\text {ob/ob }}$ mice, acute peripheral leptin injection $60 \mathrm{~min}$ before the GTT did not improve glucose tolerance in either strain (Fig. 2c). These data confirm that the effect of leptin on glucose homeostasis is specifically mediated through leptin receptors expressed in the forebrain.

It has been proposed that leptin action on glucose homeostasis involves the PI3K pathway (Mauvais-Jarvis et al., 2002; Niswender et al., 2003; Morton et al., 2005; Hill et al., 2009). As, in previous work, we had not observed leptin-induced activation of AKT in the hypothalamus (Tups et al., 2010), we sought to test whether hypothalamic PI3K signaling was involved in the leptin- 

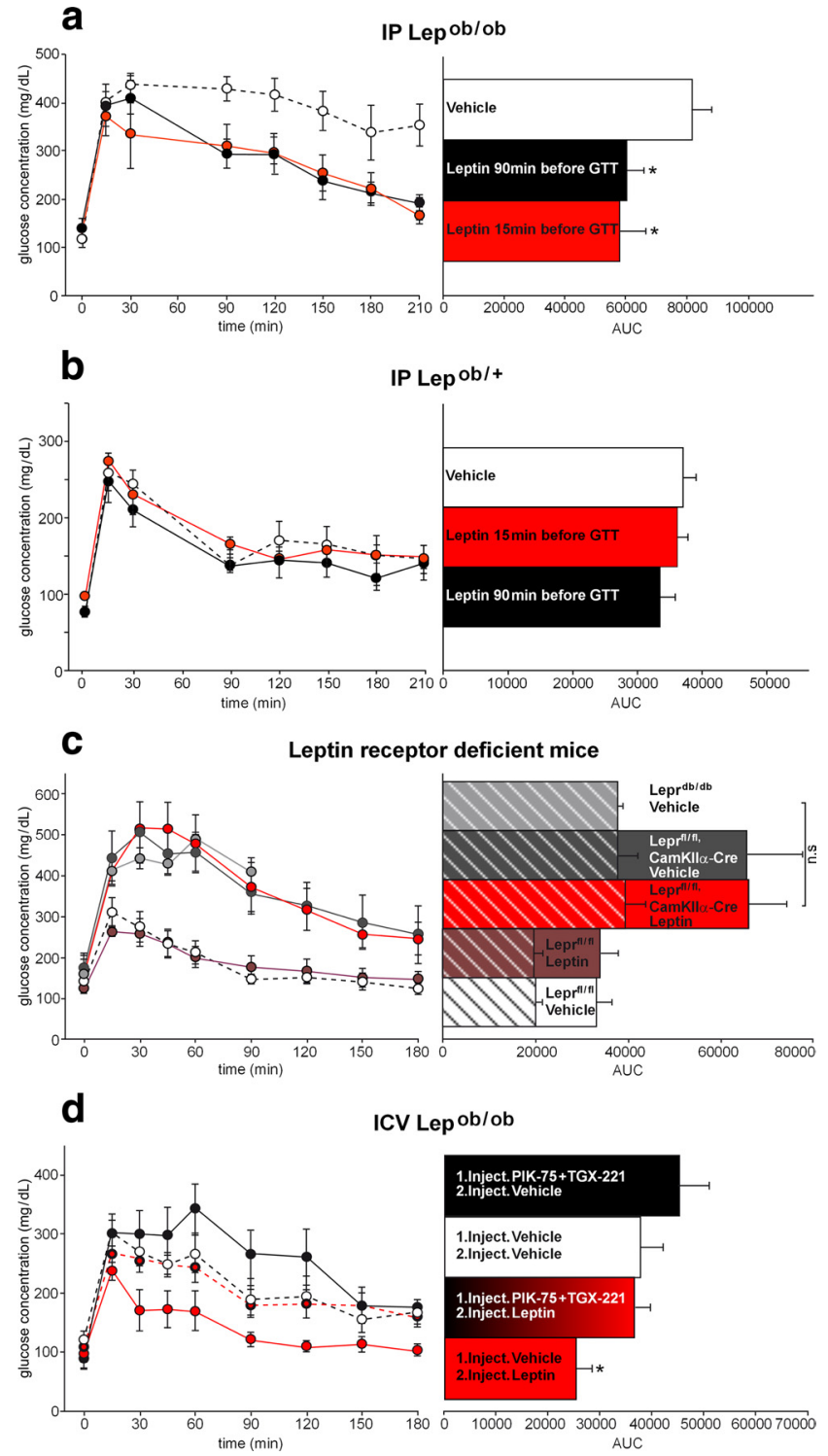

Figure 2. Glucose concentrations (left) and associated AUC (right) during ipGTT in a range of leptin-and leptin receptor-deficient mice. $\boldsymbol{a}$, Leptin very acutely improves glucose tolerance in obese, ad libitum-fed Lep ${ }^{\mathrm{ob} / \mathrm{ob}}$ mice $(1.25 \mathrm{mg} / \mathrm{kg}$, i.p.). AUC was significantly decreased by leptin pretreatment compared with PBS-pretreated Lep ${ }^{\mathrm{ob} / \mathrm{ob}}$ mice, independent of the injection time. White, Vehicle (PBS); black: intraperitoneal leptin injection 90 min before glucose application; red, intraperitoneal leptin injection 15 min before glucose application. Vehicle, $n=4$ animals; leptin, $n=5$ animals/ group; Data show means \pm SEM. ${ }^{*} p<0.05 . \boldsymbol{b}$, Heterozygous controls to experiment presented in $\boldsymbol{a}$. Leptin had no effect on normal glucose tolerance in Lep ${ }^{\mathrm{ob} /+}$ mice. White, Vehicle (PBS); black, intraperitoneal leptin injection 90 min before glucose application; red, intraperitoneal leptin injection 15 min before glucose application. Vehicle, $n=6$ animals; leptin, $n=5$ animals/group; Data show means \pm SEM. c, Leptin $(1.25 \mathrm{mg} / \mathrm{kg}$, i.p.) did not ameliorate the glucose tolerance and AUC of mice lacking leptin receptor in the forebrain. White, Lepr ${ }^{f / f t}$ mice (lean, $n=6$ ) received a vehicle (PBS) injection; brown, Lepr ${ }^{f / f l}$ mice $(n=5)$ received a leptin injection; dark gray, Lepr ${ }^{f / f l} \times C_{\text {CaMKIl } \alpha \text {-Cre }}$ mice (obese, $n=6$ ) received a vehicle (PBS) injection; red, Lepr ${ }^{f / f l} \times$ CaMKIII $^{\prime}$-Cre mice $(n=5)$ received a leptin injection; light gray, Lepr ${ }^{\mathrm{db} / \mathrm{db}}$ mice (obese, $n=5$ ) received a vehicle (PBS) injection. Since the GTT for the Lepr ${ }^{\mathrm{db} / \mathrm{db}}$ mice was terminated after 90 min, two AUCs are presented. Shaded bars show the AUC of all treatment groups over $90 \mathrm{~min}$, while plain bars show AUC of all treatment groups (except Lepr ${ }^{\mathrm{db} / \mathrm{db}}$ mice) over 180 min. Data show means \pm SEM. n.S., Nonsignificant. $\boldsymbol{d}$, Central application of leptin 60 min before ipGTT $(1 \mathrm{~g} / \mathrm{kg})$ ameliorated the glucose tolerance similar to intraperitoneal injection of the hormone. The effect was completely blocked by intracerebroventricular pretreatment with isoform selective PI3K inhibitors PIK-75 (specific for p110 $\alpha$ ) and TGX-221 specific for (p110 $\beta$ ). Inhibitors ( $0.1 \mathrm{~nm}$ each) were given 45 min before intracerebroventricular leptin injection (4 $\mu \mathrm{g}$ ). White, Vehicle (aCSF/5\% DMSO)/vehicle (aCSF), $n=5$ animals; red, vehicle (aCSF/5\% DMSO)/leptin, $n=5$ animals; black, PIK-75 + TGX 221/aCSF, $n=6$ animals; black/red, PIK-75 + TGX 221/leptin, $n=6$ animals. Data show means \pm SEM. ${ }^{*} p<0.05$. induced normalization of glucose homeostasis in Lep ${ }^{\text {ob/ob }}$ mice. To do this, we examined glucose tolerance in the presence of combined inhibition of the $\mathrm{p} 110 \alpha$ - and $\mathrm{p} 110 \beta$-isoforms of PI3K (Tups et al., 2010). Selective inhibitors of these two proteins $(0.1$ nM each) were administered into the lateral ventricle (intracerebroventricularly) of Lep ${ }^{\text {ob/ob }}$ mice 45 min before intracerebroventricular injection of leptin $(4 \mu \mathrm{g})$ or vehicle. Sixty minutes later, a GTT was performed. As expected glucose tolerance was markedly impaired in vehicle-treated Lep ${ }^{\mathrm{ob} / \mathrm{ob}}$ mice. Consistent with the data showing that central actions of leptin mediate the effect on glucose homeostasis, an acute intracerebroventricular injection of leptin significantly improved glucose tolerance in Lep ${ }^{\text {ob/ob }}$ mice, as effectively as peripheral injection in earlier experiments ( $p=0.047$; Fig. $2 d$ ). The PI3K inhibitors had no effect in vehicle-treated animals but markedly reduced the effect of leptin on peripheral glucose tolerance ( $p=0.025$; Fig. $2 d$ ).

To investigate the mechanisms activating PI3K, we measured phosphorylation of AKT in hypothalamic neurons following administration of leptin, or insulin, or a combination of the two hormones. AKT is a key target of PI3K activity and phosphorylation results in activation of this molecule. Phospho-AKT (Ser473) was measured by immunohistochemistry using a phospho-specific antibody in the mouse brain. Mice were killed 15 min after an intraperitoneal insulin injection, and cells immunoreactive for phospho-AKT (Ser473) were counted in the arcuate nucleus (ARC) (Tups et al., 2010). In lean heterozygous Lep $^{\text {ob/+ }}$ mice, acute intraperitoneal injection of insulin resulted in a marked increase in phospho-AKT (Ser473)-immunoreactive cells in the ARC $(p=0.024 ;$ Fig. $3 a, b)$. In contrast, acute peripheral leptin injection only marginally induced phospho-AKT (Ser473), and the combined administration of leptin followed 15 min later by insulin was no more effective than insulin alone. In obese Lep $^{\text {ob/ob }}$ mice, however, there was a significant $60 \%$ reduction in the number of insulin-induced phospho-AKT (Ser473)immunoreactive cells in the ARC compared with the lean littermates. Similar to lean animals, leptin treatment alone had no effect on phospho-AKT (Ser473) expression in Lep ${ }^{\text {ob/ob }}$ mice. Pretreatment with leptin, however, markedly enhanced the response to an insulin injection 15 min later (vehicle vs insulin nonsignificant; vehicle vs leptin + insulin: $p=0.009$; Fig. $3 a$ ) such that it was similar to that seen in lean controls. We repeated these studies in mice lacking a functional leptin receptor, either specifically in forebrain neurons $\left(\right.$ Lepr $^{f l / f l} \times$ CaMKII $\alpha$-Cre $)$ or globally $\left(\right.$ Lepr $\left.\mathrm{db}^{\mathrm{db}}\right)$. In both of these strains of mice, the number of cells in the ARC which showed insulin-induced phosphorylation of AKT (Ser473) was reduced to $\sim 30 \%$ of that observed in control mice $(p<0.05$; Fig. $3 c, d)$.

Up to this stage, all data has been generated using mice with genetic disruptions of leptin or leptin signal transduction, raising the question of whether this phenomenon might be specific to this extreme form of leptin deficiency or leptin resistance. Hence, in parallel studies, we sought to investigate the interaction between leptin and insulin signaling in a more physiological model. To do this, we acutely suppressed leptin signaling in lean, nondiabetic Sprague Dawley rats using a competitive leptin receptor antagonist (Solomon et al., 2006) that has been shown to block leptin-induced phospho-STAT3 in the brain (Zhang et al., 2007). A specific leptin receptor antagonist $(200 \mu \mathrm{g})$ or vehicle was injected intracerebroventricularly immediately followed by insulin or vehicle intracerebroventricularly, and animals were transcardially perfused with $4 \%$ paraformaldehyde 15 min later. As seen in mice studies, intracerebroventricular insulin resulted in a significant increase of phospho-AKT (Ser473) in the ARC. Acute 
treatment with the leptin antagonist, however, completely prevented this effect of insulin ( $p=0.015$; Fig. $3 e$ ).

The data above strongly suggested that leptin acts acutely in the brain to enhance sensitivity to central insulin signaling through the PI3K pathway. However, the mechanism by which leptin acts to acutely sensitize insulin signaling in the hypothalamus is unknown at present. Since our work has suggested that leptin, by itself, does not significantly activate AKT, we suspect that it must be acting upstream in the PI3K pathway. Insulin is thought to induce tyrosine phosphorylation of either insulin receptor substrate (IRS) 1 or 2 in the brain (Folli et al., 1994; Yamada et al., 1997; Kubota et al., 2004; Lin et al., 2004; Choudhury et al., 2005; Taguchi et al., 2007). The ability of IRS proteins to signal, however, is regulated by the degree to which IRS is serine phosphorylated on a number of different sites (Harrington et al., 2004). To test the hypothesis that leptin might directly affect serine phosphorylation of IRS1, Lep ${ }^{\text {ob/ob }}$ mice were treated with intracerebroventricular leptin or vehicle 15 min before an intraperitoneal glucose injection (to mimic the conditions during an intraperitoneal GTT). Fifteen minutes after glucose treatment, the mice were transcardially perfused with paraformaldehyde and immunohistochemistry was performed for phosphoIRS1 (Ser307 and Ser612, in separate sections) on cryosections throughout the ARC. Leptin significantly reduced the number of phospho-IRS1 (Ser612)-immunoreactive cells by $\sim 50 \%$ compared with the control (glucose-only) group $(p<0.001)$ (Fig. 4a, left). Interestingly, for phospho-IRS1 (Ser307) leptin had the opposite effect and increased the number of immunoreactive cells by $\sim 40 \%$ ( $p<$ 0.001 ) (Fig. $4 a$, right).

\section{Discussion}

Leptin has been implicated in regulating glucose homeostasis in a wide range of studies. It has been known for a long time that leptin deficiency results in the development of severe type 2 diabetes, both in humans and experimental animals (Zhang et al., 1994; Segal et al., 1996). Leptin treatment reverses these symptoms, associated with weight loss. Recent studies, however, have demonstrated that leptin can improve glucose metabolism independent of its effects on energy homeostasis (German et al., 2010; Hedbacker et al., 2010). Although it has been reported that leptin might exert its anti-diabetic properties by preferentially enhancing insulin signaling in the liver (German et al., 2010), whether leptin also modulates hypothalamic insulin signaling is only poorly understood. A wide range of studies have demonstrated that insulin signaling in the brain plays a major

a
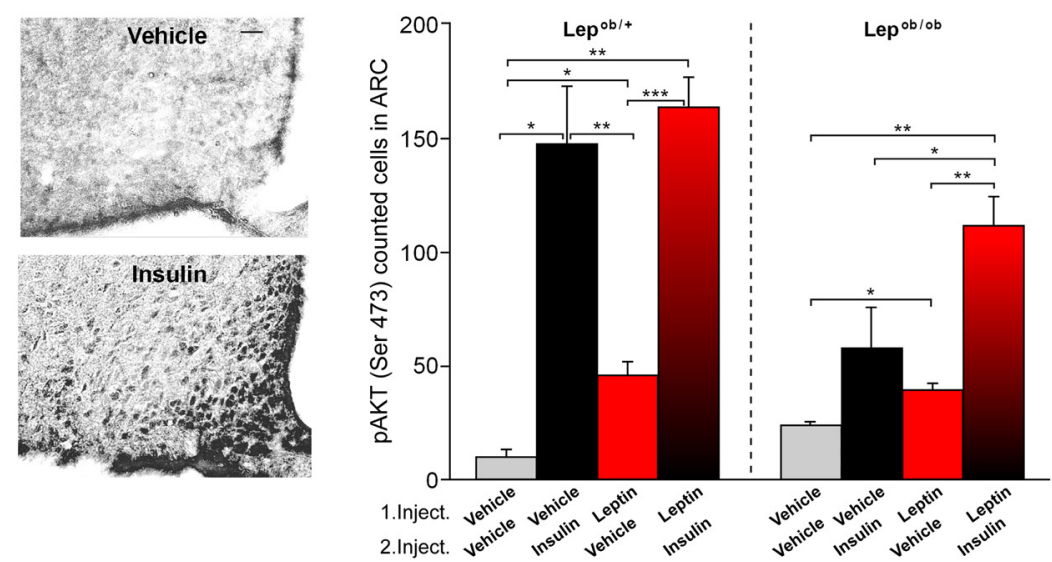

d

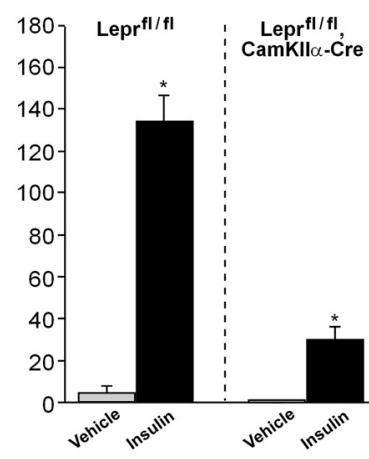

e
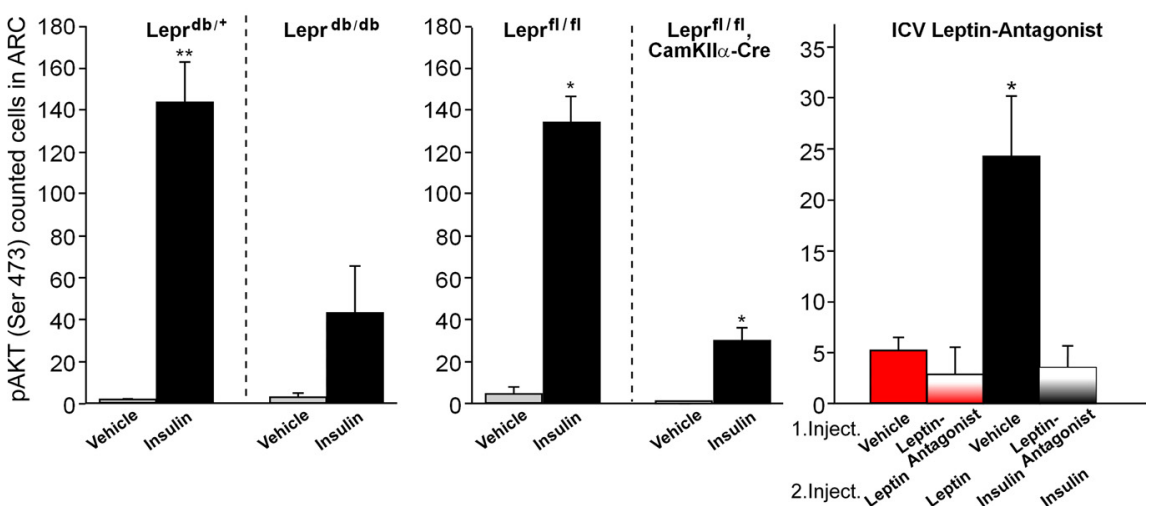

Figure 3. Crosstalk of insulin and leptin on phosphorylation of AKT(Ser 473) in the ARC. $\boldsymbol{a}$, Representative images showing phospho-AKT(Ser473) immunoreactivity in the ARC of Lep ${ }^{\mathrm{ob} /+}$ mice. Mice received either two vehicle (PBS) injections (top), or a vehicle followed by an insulin injection (1 mg/kg, bottom). Scale bar, $30 \mu \mathrm{m} . \boldsymbol{b}$, Insulin signaling is impaired in the ARC of Lep ${ }^{\text {ob/ob }}$ mice and can be restored by leptin replacement. Lep ${ }^{\text {ob/ob }}$ and Lep ${ }^{\text {ob/+ }}$ mice received two intraperitoneal injections 15 min apart with either vehicle/vehicle, vehicle/insulin, leptin/vehicle, or leptin/insulin. In Lep ${ }^{\mathrm{ob} /+}$ mice, insulin (1 mg/kg) markedly increased the number of phospho-AKT (Ser 473)-immunoreactive cells in the ARC, whereas leptin $(2 \mathrm{mg} / \mathrm{kg}$ ) had only a minor effect. Leptin did not further enhance the action of insulin. In Lep ${ }^{\mathrm{ob} / \mathrm{ob}}$ mice, insulin signaling was impaired as reflected in a decrease in insulin-induced phospho-AKT expression. Leptin pretreatment, however, could partially restore insulin signaling in the leptin/ insulin group. Vehicle, $n=2$ animals/group; insulin, leptin, and leptin/insulin, $n=4$ animals/group. Data show means $\pm S E M$. ${ }^{*} p<0.05,{ }^{* *} p<0.01,{ }^{* * *} p<0.001$. c, Leptin receptor-deficient mice exhibit impaired insulin signaling in the ARC. Lepr ${ }^{\mathrm{db} / \mathrm{db}}$ mice and their controls (Lepr ${ }^{\mathrm{db} /+}$ ) received an intraperitoneal insulin injection $(1 \mathrm{mg} / \mathrm{kg}) 15 \mathrm{~min}$ before transcardial perfusion. phospho-AKT(Ser473)-immunoreactive cells were counted in the ARC. Gray bars depict the vehicle (PBS)-treated whereas the black bars depict the insulin ( $1 \mathrm{mg} / \mathrm{kg}$ )-treated groups of the respective genotype $(n=3-6)$. Data show means \pm SEM. $\boldsymbol{d}$, Mice with a neuron-specific deletion of the leptin receptor $\left(\right.$ Lepr $\left.^{f / f l} \times \mathrm{CaMKIl}_{\alpha}-\mathrm{Cre}\right)$ also exhibit impaired insulin signaling in the hypothalamus. The experimental paradigm was identical to Figure $3 c$, and the respective controls were Lepr ${ }^{\mathrm{fl} / \mathrm{fl}}$ mice. Vehicle $n=$ 3 animals/group; insulin $n=5$ animals/group. Data show means \pm SEM. ${ }^{*} p<0.05,{ }^{* *} p<0.01$. e, A leptin receptor antagonist blocks insulin-induced pAKT in healthy, nondiabetic Sprague Dawley rats. The leptin antagonist was injected ( $200 \mu \mathrm{g})$ immediately before insulin $(10 \mathrm{mU})$ was injected. One group received a vehicle injection (aCSF) followed by leptin (4 $\mu \mathrm{g})$, one the antagonist, followed by leptin (4 $\mu \mathrm{g}$ ), and one vehicle (aCSF) followed by insulin (10 mU). The insulin-induced phosphorylation of AKT (Ser473) was blocked by an intracerebroventricular injection of the leptin antagonist (200 $\mu \mathrm{g})$ directly before insulin injection. All injections were intracerebroventricular. Red, aCSF/leptin, $n=3$ animals; red/white, leptin antagonist/leptin, $n=3$ animals; black, aCSF/insulin, $n=4$ animals; black/white, leptin antagonist/insulin, $n=4$ animals. ${ }^{*} p<0.05$.

role in maintaining peripheral glucose homeostasis (Brüning et al., 2000; Gelling et al., 2006; Koch et al., 2008; Obici et al., 2002a,b). Here, we corroborate the notion that central insulin signaling is a major factor controlling peripheral glucose homeostasis. Moreover, we present evidence that insulin action in the hypothalamus is dependent on intact leptin signaling in the brain.

In our first experiment, we demonstrated that leptin, itself, is a major contributor to an enhanced glucose tolerance, and that this action is very acute and does not require a leptin-induced 


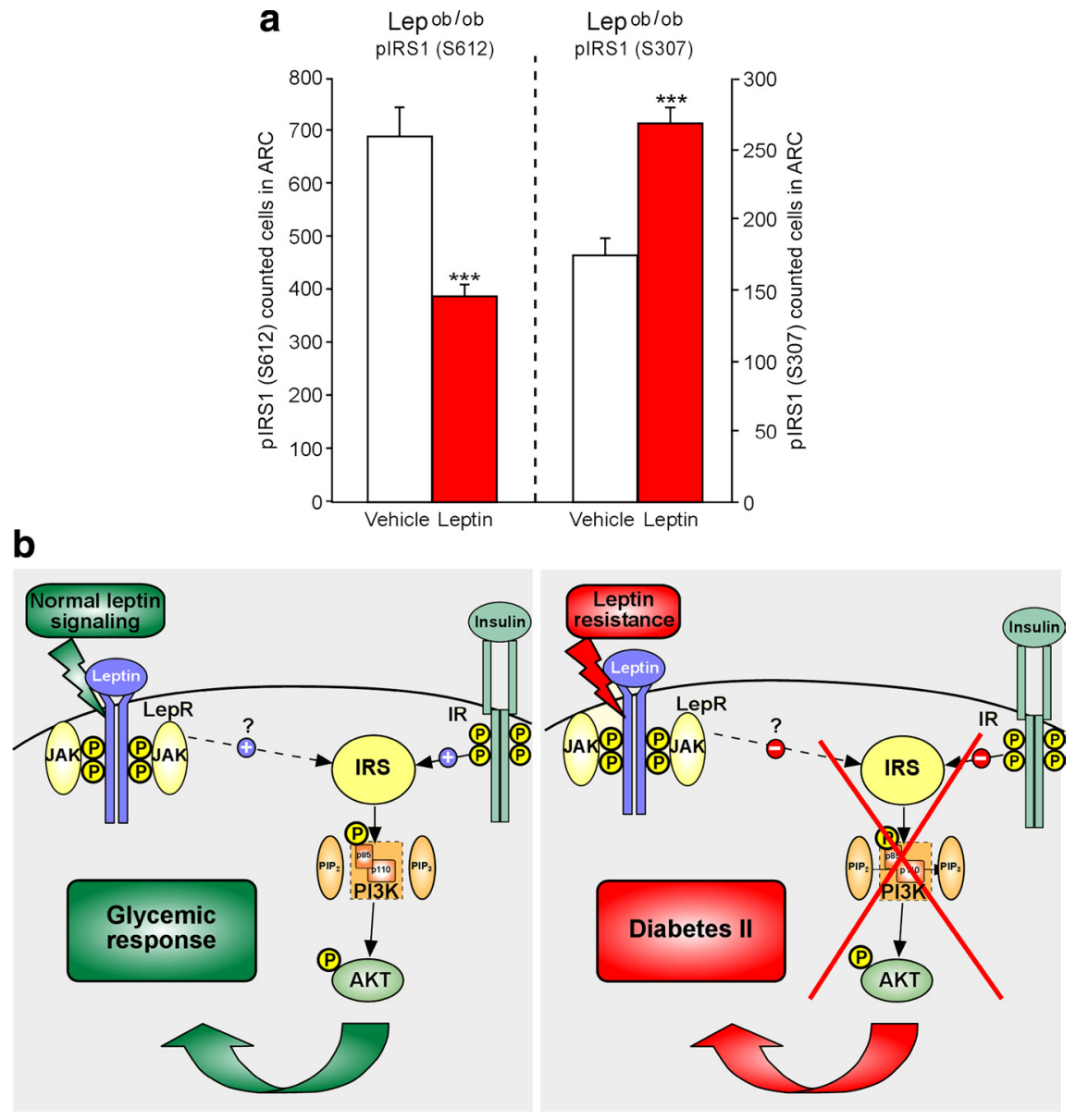

Figure 4. IRS phosphorylation in the hypothalamus: a potential mechanism for leptin's action on glycemia? $\boldsymbol{a}$, Analysis of phospho-IRS1(Ser612) (left) and for phospho-IRS1(Ser307) (right) by immunohistochemistry in the ARC of Lep ${ }^{\mathrm{ob} / \mathrm{ob}}$ mice $(n=$ 5-6 animals/group). phospho-IRS1-immunoreactive cells within the medial part of the ARC were counted in four region-matched representative sections of each animal. Fifteen minutes after either vehicle (aCSF) or leptin $(4 \mu \mathrm{g})$ intracerebroventricular injection, animals were transcardially perfused. Data show means \pm SEM. ${ }^{* * *} p<0.001$. $b$, Model proposing the central mechanism of sensitization of insulin signaling by leptin. In nonobese, leptin-sensitive animals, leptin might activate IRS1 to promote insulin action through the IRS1-PI3K pathway to regulate glucose homeostasis (left). During obesity, with the onset of leptin resistance, leptin might lose its ability to activate IRS1, resulting in a modification of this molecule to a lower affinity to insulin signal transduction (right). This will result in chronically impaired insulin signaling and the development of type 2 diabetes. LepR, Leptin receptor; IR, insulin receptor; JAK, Janus kinase.

reduction of body weight and loss of body fat mass. Pair-feeding and subsequent food restriction of Lep ${ }^{\mathrm{ob} / \mathrm{ob}}$ mice to reduce body weight to the level of lean $\mathrm{Lep}^{\mathrm{ob} /+}$ mice only revealed a trend toward an improvement in glucose tolerance. There was no correlation between body fat content and glucose tolerance [area under the curve (AUC) ] in these individuals. Only after adding an acute leptin injection was glucose tolerance significantly improved, resulting in even better clearance than in vehicle-treated Lep ${ }^{\mathrm{ob} /+}$ controls. Thus, lack of leptin, rather than the associated obesity, was the primary cause of impaired glucose homeostasis in Lep ${ }^{\mathrm{ob} / \mathrm{ob}}$ mice. These data are consistent with the hypothesis that leptin resistance is a primary cause of type 2 diabetes. However, the possibility that some additional adverse effects are caused by excessive adipose tissue cannot be eliminated, since there was some trend toward an improvement in glucose tolerance simply after pair-feeding/ food restriction in Lep $^{\text {ob/ob }}$ mice. Corticosteronemia, glucagon and circulating catecholamines could potentially contribute to observed outcomes and warrant future investigation.

The effect of leptin on glucose metabolism was exclusively mediated centrally, because leptin was equally effective whether administered centrally or peripherally, and there was no beneficial effect of leptin in mice lacking a functional leptin receptor specifically in forebrain neurons. Surprisingly, leptin was able to act very acutely (within $15 \mathrm{~min}$ ) to improve glucose tolerance. This suggests that the effect is not mediated through enhanced transcription of leptin target genes, but rather through more rapid effects such as phosphorylation events or acute changes in the neuronal firing rate. Crosstalk of both hormones particularly in proopiomelanocortin neurons of the hypothalamus has been suggested. Both insulin and leptin induced a transient nuclear export of FoxO1 from these neurons (Fukuda et al., 2008) and affected neuronal firing in a PI3K-dependent manner (Hill et al., 2008). A recent report suggests that this crosstalk may be mediated through segregated actions of leptin and insulin on distinct cells within the POMC network, rather than on the same cells (Williams et al., 2010).

In the present study, inhibition of the p $110 \alpha$ and $\beta$ isoforms of PI3K totally blunted the glycemic action of leptin, suggesting that leptin-induced enhancement of glucose homeostasis is dependent on $\mathrm{PI} 3 \mathrm{~K}$ signaling in the brain. In our previous work in rats (Tups et al., 2010), we demonstrated that leptin did not directly activate phospho-AKT, the primary target of PI3K-activity in the hypothalamus. Hence, we hypothesized that the suppression of leptin action that occurred following inhibition of PI3K might be based on disruption of insulin signaling. Consistent with this interpretation, in Lep ${ }^{\mathrm{ob} /+}$ mice we observed that the ability of insulin to activate phospho-AKT was much higher than that of leptin, but that this effect of insulin was markedly reduced in all of the models with impaired leptin signaling; the Lep ${ }^{\mathrm{ob} / \mathrm{ob}}$, the Lepr ${ }^{\mathrm{db} / \mathrm{db}}$ and the Lepr ${ }^{f l / f l} \times$ CaMKII $\alpha$-Cre mouse. In the Lep ${ }^{\text {ob/ob }}$ mouse, which is leptindeficient but remains responsive to leptin, leptin treatment acutely restored insulin sensitivity, suggesting a potent crosstalk of the two hormones. The sensitization of insulin signaling by leptin was not limited to mouse models with extreme metabolic and neuroendocrine derangements, such as genetic modification. Acute antagonism of central leptin action in healthy nondiabetic rats totally impaired the number of insulin-induced phospho-AKT-immunoreactive cells in the arcuate nucleus, confirming the essential role of leptin in maintaining insulin sensitivity in the hypothalamus.

Unlike our previous work in rats, in the present study in mice, leptin was able to induce a small increase in phospho-AKT in the arcuate nucleus. Because PI3K inhibition completely prevented the leptin-induced enhancement of glucose homeostasis, it is possible that this effect of leptin is mediated by a direct action on PI3K. It seems more likely, however, that the marked improvement in glucose homeostasis observed after leptin treatment was 
due to the leptin-induced sensitization of insulin signaling in the hypothalamus. As a possible mechanism for this effect, we hypothesized that leptin stimulated insulin signaling through PI3K, through an action upstream of PI3K at the level of IRS1. We observed that leptin reduced the number of phosphoIRS1(Ser612)-immunoreactive cells in the arcuate nucleus and had the opposite effect for phospho-IRS1(Ser307). Whether serine phosphorylation of IRS1 negatively or positively regulates insulin signaling in vivo is only poorly understood. In most studies, serine phosphorylation at multiple sites is associated with insulin resistance (Harrington et al., 2004). Hence, leptininduced reduction in Ser612 phosphorylation of IRS1 may promote sensitivity to insulin signaling. However, the effect of leptin on serine phophorylation of IRS1 was not uniform at all sites examined. We also observed a leptin-induced increase in Ser307 phosphorylation. Very recently, Ser307 phosphorylation of IRS1 was shown to be essential for maintaining insulin sensitivity in mice, with insulin resistance occurring in mice in which Ser307 was replaced with alanine (Copps et al., 2010). Leptin-induced Ser307 phosphorylation of IRS1, therefore, may also sensitize insulin action in the hypothalamus. These data are consistent with the hypothesis that leptin may directly regulate insulin sensitivity in the hypothalamus, at least in part, through specific modulation of serine phosphorylation on IRS1 at multiple sites (Fig. 4b).

Our data support the concept that central insulin signaling is a major factor controlling peripheral glucose homeostasis. Previous studies have demonstrated that hypothalamic insulin signal transduction is required for the inhibition of hepatic glucose production (Obici et al., 2002a,b) and that hypothalamic actions of leptin appear to improve peripheral insulin sensitivity via a mechanism involving the vagus nerve (German et al., 2009). Furthermore, it was reported that hepatic glucose production is controlled by central nutrient sensing mechanisms (Pocai et al., 2005). The results presented above provide a key link between these important observations. We have shown that leptin is essential for insulin action in the hypothalamus, allowing central insulin to maintain blood glucose homeostasis. The profound correlation of obesity with type 2 diabetes can therefore be explained by the onset of hypothalamic leptin resistance associated with obesity. This results in a loss of insulin sensitivity and consequent impaired glucose homeostasis.

\section{References}

Brüning JC, Gautam D, Burks DJ, Gillette J, Schubert M, Orban PC, Klein R, Krone W, Müller-Wieland D, Kahn CR (2000) Role of brain insulin receptor in control of body weight and reproduction. Science 289:2122-2125.

Choudhury AI, Heffron H, Smith MA, Al-Qassab H, Xu AW, Selman C, Simmgen M, Clements M, Claret M, Maccoll G, Bedford DC, Hisadome K, Diakonov I, Moosajee V, Bell JD, Speakman JR, Batterham RL, Barsh GS, Ashford ML, Withers DJ (2005) The role of insulin receptor substrate 2 in hypothalamic and beta cell function. J Clin Invest 115:940-950.

Copps KD, Hancer NJ, Opare-Ado L, Qiu W, Walsh C, White MF (2010) Irs1 serine 307 promotes insulin sensitivity in mice. Cell Metab 11:84-92.

Farooqi IS, Jebb SA, Langmack G, Lawrence E, Cheetham CH, Prentice AM, Hughes IA, McCamish MA, O'Rahilly S (1999) Effects of recombinant leptin therapy in a child with congenital leptin deficiency. N Engl J Med 341:879-884.

Folli F, Bonfanti L, Renard E, Kahn CR, Merighi A (1994) Insulin receptor substrate-1 (IRS-1) distribution in the rat central nervous system. J Neurosci 14:6412-6422.

Fukuda M, Jones JE, Olson D, Hill J, Lee CE, Gautron L, Choi M, Zigman JM, Lowell BB, Elmquist JK (2008) Monitoring FoxO1 localization in chemically identified neurons. J Neurosci 28:13640-13648.

Gelling RW, Morton GJ, Morrison CD, Niswender KD, Myers MG Jr, Rhodes
CJ, Schwartz MW (2006) Insulin action in the brain contributes to glucose lowering during insulin treatment of diabetes. Cell Metab 3:67-73.

German J, Kim F, Schwartz GJ, Havel PJ, Rhodes CJ, Schwartz MW, Morton GJ (2009) Hypothalamic leptin signaling regulates hepatic insulin sensitivity via a neurocircuit involving the vagus nerve. Endocrinology 150:4502-4511.

German JP, Wisse BE, Thaler JP, Oh-IS, Sarruf DA, Ogimoto K, Kaiyala KJ, Fischer JD, Matsen ME, Taborsky GJ Jr, Schwartz MW, Morton GJ (2010) Leptin deficiency causes insulin resistance induced by uncontrolled diabetes. Diabetes 59:1626-1634.

Harrington LS, Findlay GM, Gray A, Tolkacheva T, Wigfield S, Rebholz H, Barnett J, Leslie NR, Cheng S, Shepherd PR, Gout I, Downes CP, Lamb RF (2004) The TSC1-2 tumor suppressor controls insulin-PI3K signaling via regulation of IRS proteins. J Cell Biol 166:213-223.

Hedbacker K, Birsoy K, Wysocki RW, Asilmaz E, Ahima RS, Farooqi IS, Friedman JM (2010) Antidiabetic effects of IGFBP2, a leptin-regulated gene. Cell Metab 11:11-22.

Hill JW, Williams KW, Ye C, Luo J, Balthasar N, Coppari R, Cowley MA, Cantley LC, Lowell BB, Elmquist JK (2008) Acute effects of leptin require PI3K signaling in hypothalamic proopiomelanocortin neurons in mice. J Clin Invest 118:1796-1805.

Hill JW, Xu Y, Preitner F, Fukuda M, Cho YR, Luo J, Balthasar N, Coppari R, Cantley LC, Kahn BB, Zhao JJ, Elmquist JK (2009) Phosphatidyl inositol 3-kinase signaling in hypothalamic proopiomelanocortin neurons contributes to the regulation of glucose homeostasis. Endocrinology 150:4874-4882.

Kievit P, Howard JK, Badman MK, Balthasar N, Coppari R, Mori H, Lee CE, Elmquist JK, Yoshimura A, Flier JS (2006) Enhanced leptin sensitivity and improved glucose homeostasis in mice lacking suppressor of cytokine signaling-3 in POMC-expressing cells. Cell Metab 4:123-132.

Koch L, Wunderlich FT, Seibler J, Könner AC, Hampel B, Irlenbusch S, Brabant G, Kahn CR, Schwenk F, Brüning JC (2008) Central insulin action regulates peripheral glucose and fat metabolism in mice. J Clin Invest 118:2132-2147.

Kubota N, Terauchi Y, Tobe K, Yano W, Suzuki R, Ueki K, Takamoto I, Satoh H, Maki T, Kubota T, Moroi M, Okada-Iwabu M, Ezaki O, Nagai R, Ueta Y, Kadowaki T, Noda T (2004) Insulin receptor substrate 2 plays a crucial role in beta cells and the hypothalamus. J Clin Invest 114:917-927.

Lin X, Taguchi A, Park S, Kushner JA, Li F, Li Y, White MF (2004) Dysregulation of insulin receptor substrate 2 in beta cells and brain causes obesity and diabetes. J Clin Invest 114:908-916.

Mauvais-Jarvis F, Ueki K, Fruman DA, Hirshman MF, Sakamoto K, Goodyear LJ, Iannacone M, Accili D, Cantley LC, Kahn CR (2002) Reduced expression of the murine p85alpha subunit of phosphoinositide 3-kinase improves insulin signaling and ameliorates diabetes. J Clin Invest 109:141-149.

Morton GJ, Gelling RW, Niswender KD, Morrison CD, Rhodes CJ, Schwartz MW (2005) Leptin regulates insulin sensitivity via phosphatidylinositol-3-OH kinase signaling in mediobasal hypothalamic neurons. Cell Metab 2:411-420.

Muzzin P, Eisensmith RC, Copeland KC, Woo SL (1996) Correction of obesity and diabetes in genetically obese mice by leptin gene therapy. Proc Natl Acad Sci U S A 93:14804-14808.

Niswender KD, Morrison CD, Clegg DJ, Olson R, Baskin DG, Myers MG Jr, Seeley RJ, Schwartz MW (2003) Insulin activation of phosphatidylinositol 3-kinase in the hypothalamic arcuate nucleus: a key mediator of insulin-induced anorexia. Diabetes 52:227-231.

Obici S, Feng Z, Karkanias G, Baskin DG, Rossetti L (2002a) Decreasing hypothalamic insulin receptors causes hyperphagia and insulin resistance in rats. Nat Neurosci 5:566 -572 .

Obici S, Zhang BB, Karkanias G, Rossetti L (2002b) Hypothalamic insulin signaling is required for inhibition of glucose production. Nat Med 8:1376-1382.

Okamoto H, Nakae J, Kitamura T, Park BC, Dragatsis I, Accili D (2004) Transgenic rescue of insulin receptor-deficient mice. J Clin Invest 114:214-223.

Okamoto H, Obici S, Accili D, Rossetti L (2005) Restoration of liver insulin signaling in Insr knockout mice fails to normalize hepatic insulin action. J Clin Invest 115:1314-1322.

Pelleymounter MA, Cullen MJ, Baker MB, Hecht R, Winters D, Boone T, Collins F (1995) Effects of the obese gene product on body weight regulation in ob/ob mice. Science 269:540-543. 
Pocai A, Obici S, Schwartz GJ, Rossetti L (2005) A brain-liver circuit regulates glucose homeostasis. Cell Metab 1:53-61.

Quennell JH, Mulligan AC, Tups A, Liu X, Phipps SJ, Kemp CJ, Herbison AE, Grattan DR, Anderson GM (2009) Leptin indirectly regulates gonadotropin-releasing hormone neuronal function. Endocrinology 150:2805-2812.

Schwartz MW, Baskin DG, Bukowski TR, Kuijper JL, Foster D, Lasser G, Prunkard DE, Porte D Jr, Woods SC, Seeley RJ, Weigle DS (1996) Specificity of leptin action on elevated blood glucose levels and hypothalamic neuropeptide Y gene expression in ob/ob mice. Diabetes 45:531-535.

Segal KR, Landt M, Klein S (1996) Relationship between insulin sensitivity and plasma leptin concentration in lean and obese men. Diabetes 45:988-991.

Solomon G, Niv-Spector L, Gonen-Berger D, Callebaut I, Djiane J, Gertler A (2006) Preparation of leptin antagonists by site-directed mutagenesis of human, ovine, rat, and mouse leptin's site III. Ann NY Acad Sci 1091:531-539.

Taguchi A, Wartschow LM, White MF (2007) Brain IRS2 signaling coordinates life span and nutrient homeostasis. Science 317:369-372.

Tups A, Anderson GM, Rizwan M, Augustine RA, Chaussade C, Shepherd PR, Grattan DR (2010) Both p110 $\alpha$ and p110 $\beta$ isoforms of phosphati- dylinositol 3-OH-kinase are required for insulin signalling in the hypothalamus. J Neuroendocrinol 22:534-542.

Williams KW, Margatho LO, Lee CE, Choi M, Lee S, Scott MM, Elias CF, Elmquist JK (2010) Segregation of acute leptin and insulin effects in distinct populations of arcuate proopiomelanocortin neurons. J Neurosci 30:2472-2479.

Yamada M, Ohnishi H, Sano S, Nakatani A, Ikeuchi T, Hatanaka H (1997) Insulin receptor substrate (IRS)-1 and IRS-2 are tyrosine-phosphorylated and associated with phosphatidylinositol 3-kinase in response to brainderived neurotrophic factor in cultured cerebral cortical neurons. J Biol Chem 272:30334-30339.

Yu X, Park BH, Wang MY, Wang ZV, Unger RH (2008) Making insulindeficient type 1 diabetic rodents thrive without insulin. Proc Natl Acad Sci U S A 105:14070-14075.

Zhang J, Matheny MK, Tümer N, Mitchell MK, Scarpace PJ (2007) Leptin antagonist reveals that the normalization of caloric intake and the thermic effect of food after high-fat feeding are leptin dependent. Am J Physiol Regul Integr Comp Physiol 292:R868-R874.

Zhang Y, Proenca R, Maffei M, Barone M, Leopold L, Friedman JM (1994) Positional cloning of the mouse obese gene and its human homologue. Nature 372:425-432. 